\title{
The effects of 7-hour local hyperglycaemia on forearm macro and microcirculatory blood flow and vascular reactivity in healthy man
}

\author{
A.J.H.M.Houben ${ }^{1}$, N.C.Schaper ${ }^{1}$, C.H.A.de Haan ${ }^{1}$, F.C.Huvers ${ }^{1}$, D. W.Slaaf ${ }^{3}$, P. W. de Leeuw ${ }^{2}$, \\ A. C. Nieuwenhuijzen Kruseman ${ }^{1}$ \\ ${ }^{1}$ Department of Internal Medicine, Division of Endocrinology, University Hospital, Maastricht, The Netherlands \\ ${ }^{2}$ Department of Internal Medicine, Division of Nephrology, University Hospital Maastricht, The Netherlands \\ ${ }^{3}$ Department of Biophysics, Cardiovascular Research Institute Maastricht, University of Limburg, Maastricht, The Netherlands
}

Summary Animal studies suggest that hyperglycaemia directly affects local blood flow and vascular reactivity. We studied the effects of $7 \mathrm{~h}$ of local forearm hyperglycaemia, on forearm (muscle) and skin microcirculatory blood flow in 12 healthy men. Furthermore, the effects of this local hyperglycaemia on forearm vasoreactivity to noradrenaline were studied. Using the perfused forearm technique, a local hyperglycaemia of approximately $16 \mathrm{mmol} / \mathrm{l}$ was induced by continuous intraarterial infusion of $5 \%$ glucose. All subjects received both glucose and placebo $(0.9 \% \mathrm{NaCl})$ infusions on two different occasions, in random order and blinded for the subjects. Forearm (muscle) blood flow and vascular reactivity to noradrenaline were measured using venous occlusion plethysmography. Skin microcirculatory blood flow was evaluated using intravital capillary microscopy (nutritive blood flow) and laser-Doppler fluxmetry (thermoregulatory blood flow). Measurements were performed at baseline, after $4 \mathrm{~h}$, and after
$7 \mathrm{~h}$ of intraarterial glucose or placebo infusion. During local glucose infusion there was a slight increase in the levels of insulin, C-peptide, systemic glucose, and blood pressure, compared to the placebo experiments. No differences were observed in forearm blood flow and laser-Doppler flux ratio (infused: contralateral arm), as well as in capillary blood cell velocity between glucose and placebo experiments. Noradrenaline produced similar reductions in forearm blood flow ratio during glucose and placebo experiments. We conclude that in contrast to animal studies, local hyperglycaemia $(\approx 16 \mathrm{mmol} / \mathrm{l})$ for $7 \mathrm{~h}$ does not affect forearm macro and microcirculatory blood flow or vascular reactivity to noradrenaline in man. [Diabetologia (1994) 37: 750$756]$

Key words Hyperglycaemia, intraarterial, forearm blood flow, microcirculation, vasoreactivity, noradrenaline.
One of the main causes of morbidity and mortality in patients with IDDM is microangiopathy. Early haemodynamic changes are probably an important initiating mechanism in the development of this microangiopathy [1]. Shortly after the onset of IDDM haemody-

Received: 26 November 1993

and in revised form: 26 February 1994

Corresponding author: Dr. A.J.H.M.Houben, University Hospital Maastricht, Department of Internal Medicine, PO Box 5800, NL-6202 AZ Maastricht, The Netherlands

Abbrevations: FBF, Forearm blood flow; LDF, laser-Doppler fluxmetry; $\mathrm{CBV}$, capillary blood cell velocity; $\mathrm{PU}$, perfusion units; $\mathrm{CV}$, coefficient of variation; MAP, mean arterial blood pressure namic changes can be observed in several organs and tissues, as has been demonstrated recently for forearm muscle [2] and skin [3]. In addition, cardiac output [4], blood flow to the kidneys [5] and retina [6], and skin capillary pressures [7] have been found to be increased in early IDDM. Most of these parameters normalize in parallel to normalization of metabolic control, which suggests that hyperglycaemia plays an important role in the development of these haemodynamic changes. Indeed, local injection or application of glucose in healthy animals results in arteriolar vasodilation, increased blood flow, and disturbed autoregulation $[8,9]$. Some of these effects can be observed a few hours after induction of local hyperglycaemia.

Besides changes in endothelium (in)dependent vasodilation $[2,8]$, diabetes induces changes in vasocon- 
strictor reactivity. Both in vitro and in vivo animal studies have shown an increased sensitivity and reactivity to noradrenaline $[10,11]$. In IDDM patients an increased reactivity to noradrenaline was also demonstrated $[12,13]$.

We demonstrated recently, that a 1-h local (forearm) moderate hyperglycaemia did not change forearm (muscle) FBF [14]. Only non-physiologic high local glucose concentrations resulted in an increase in FBF. These findings, in combination with those of aforementioned animal studies, suggest that several hours of local hyperglycaemia are required to induce haemodynamic changes. The present study was undertaken to determine the effects of a 7-h local (forearm) hyperglycaemia, induced by intraarterial infusion of glucose, on basal FBF, and on skin thermoregulatory and nutritive microcirculatory blood flow in healthy men. Furthermore, the effects of this local hyperglycaemia on forearm vasoreactivity to noradrenaline, a physiological endogenous vasoconstrictor, was evaluated. To correct for possible systemic effects of local glucose infusion and possible diurnal variations in vasoconstrictor response to noradrenaline, the experiments were placebo controlled.

\section{Subjects and methods}

Experiments were performed in 12 healthy male volunteers (recruited from a student population), with a mean age of $23.6 \pm 3.1$ (SD) years and a body mass index of $23.0 \pm 3.1$ (SD) $\mathrm{kg} / \mathrm{m}^{2}$. The number of subjects was based on earlier studies [14]. Forearm volume was measured by water displacement. Mean forearm volume (from elbow to wrist), of the non-dominant arm was $1226 \pm 225$ (SD) $\mathrm{ml}$, and the volume of the dominant arm was $1304 \pm 226 \mathrm{ml}$. Three subjects were smokers (their results were similar to those of the non-smokers). All participants gave written informed consent and the study was approved by the medical ethical committee of the Maastricht University Hospital.

Protocol. The subjects received both glucose and placebo $(0.9 \%$ $\mathrm{NaCl}$ ) infusions, single-blind in random order with a 2-3 week interval. All experiments started at 08.00 hours and were performed in a quiet, temperature-controlled room (mean temperature $24.9 \pm 0.2(\mathrm{SD}){ }^{\circ} \mathrm{C}$ ). Precautions were taken to minimize external disturbances. Subjects were studied in the supine position. Between the measurements the subjects were allowed to sit upright (by raising the head of the bed to the vertical position), but $15 \mathrm{~min}$ before each measurement they were placed supine again. The subjects were not allowed to smoke, eat, or drink (except for water) from 22.00 hours the night before the experiment until the end of the experiment. Three catheters were inserted: a 20 gauge catheter into the brachial artery (retrogradely) in the cubital fossa of the non-dominant arm, for infusion of glucose/saline and noradrenaline, and in both arms a catheter was inserted into the antecubital vein (anterogradely), for blood sampling. Venous blood from the infused arm was drawn to determine local glucose level (at 10.15 hours, and every $30 \mathrm{~min}$ after the start of the glucose infusion; during the placebo experiments at 10.15, $12.30,14.30$, and 17.30 hours), pyruvate and lactate levels (at $10.15,14.30$ and 17.30 hours), and adrenaline and noradrenaline levels (at 10.15 and 17.30 hours). Insulin, C-peptide (at 10.15, $12.30,14.30$, and 17.30 hours), and "systemic" blood glucose levels (at the same time as local glucose levels), were determined in venous blood from the contralateral arm. The catheters were kept patent with saline ( $\mathrm{NaCl} 0.9 \%)$.

Baseline measurements of (micro)circulatory blood flow started at 10.15 hours, and were performed in the following order: CBV, LDF, and FBF (before and during three doses of noradrenaline). After these measurements (10.30 hours), the intraarterial infusion of $5 \%$ glucose or saline was started. The rates of infusion were individually calculated using the basal FBF measurement and forearm volume, to raise forearm blood glucose levels by about $12 \mathrm{mmol} / \mathrm{l}$. The same calculations for infusion rate were used for saline infusion. The mean infusion rate was $126 \pm 48(\mathrm{SD}) \mathrm{ml} / \mathrm{h}$. At 14.30 hours (after $4 \mathrm{~h}$ ) and at 17.30 hours (after $7 \mathrm{~h}$ of local forearm hyperglycaemia), another set of haemodynamic measurements was performed.

Methods. CBV (representing skin nutritive blood flow) was monitored using epi-POL videomicroscopy, with a Leitz L $20 \times$ lens (numeric aperture: 0.32). Images of two capillaries in the distal row of the fourth finger nailfold of the infused arm were recorded during $2 \mathrm{~min}$. The images were videotaped for off-line analysis. The same two capillaries were studied during each subsequent measurement. Mean CBV of the two capillaries was used for calculations (with a coefficient of variation (CV) of $31 \%$ comparing two consecutive CBV measurements), which was evaluated off-line using the temporal correlation technique [15] incorporated in CAPIFLOW software (SIM, Kista, Sweden). Capillary diameter was measured as the width of the erythrocyte column in the arteriolar and venular limb. In five subjects, image quality was not sufficient to determine CBV at all time points throughout both experiments. CBV was not studied in the contralateral arm, due to immobility of the equipment.

Thermoregulatory skin perfusion was determined using LDF (Periflux PF3; Perimed, Järfälla, Sweden), with two probes PF 308, wide band $(12 \mathrm{kHz})$ mode, and time constant $0.2 \mathrm{~s}$. The probes were placed on the dorsum of the interphalanx of the fourth finger of both hands. These probes remained in the same position throughout the experiment. The mean value of the 2 min recording was used for calculations (with a CV of $16 \%$ comparing two consecutive LDF measurements). Flux values are expressed as arbitrary PU, calibrated against an external standard. Biological zero values, obtained during arterial occlusion, were subtracted from the measured LDF levels. Mean biological zero value (pooled for all measurements) was 4.5 \pm 1.7 PU. Skin temperature was measured at the same site (infused arm) using a Hewlett Packard 78214C monitor (Hewlett Packard; Böblingen, Germany).

FBF was determined in both arms simultaneously using ECG-triggered strain gauge venous occlusion plethysmography (Periflow; Janssen Scientific Instruments, Beerse, Belgium). The hand circulation was excluded during the FBF measurement by inflating a wrist cuff to suprasystolic pressure, starting 1 min before each FBF measurement. Hence, FBF measurements predominantly represent muscle blood flow [16]. FBF was measured during 11 min: 2 min of baseline FBF and during three cumulative doses of noradrenaline (Centrafarm, Etten-Leur, The Netherlands): $0.025,0.1$, and $0.4 \mu \mathrm{g} / \mathrm{min}$ (each dose was infused for $3 \mathrm{~min}$; doses were based on a pilot study; unpublished data). The mean value of the last min of each period was used for calculations (with a CV of $14 \%$ comparing two consecutive FBF measurements). The CV of repeated measures of the vasoconstrictor response to the highest dose of noradrenaline $(0.4 \mu \mathrm{g} / \mathrm{min})$ during the day is $13 \%$. A flow curve lasted five heartbeats, with venous occlusion $(50 \mathrm{~mm} \mathrm{Hg})$ applied during three beats. Therefore, on the average 12 inflow curves per min were determined. 
Table 1. Mean blood glucose, insulin, C-peptide, pyruvate, lactate, noradrenaline, and adrenaline levels during the glucose and placebo experiments

\begin{tabular}{|c|c|c|c|c|c|}
\hline & 10.15 hours & 12.30 hours & 14.30 hours & 17.30 hours & $p$-level \\
\hline Glucose (i) (mmol/l) & $4.3 \pm 0.4$ & $4.2 \pm 0.5$ & $4.1 \pm 0.4$ & $4.1 \pm 0.4$ & 0.28 \\
\hline C-peptide (cl) (nmol/l) & $0.38 \pm 0.12$ & $0.35 \pm 0.11$ & $0.29 \pm 0.06$ & $0.25 \pm 0.08$ & 0.0001 \\
\hline Pyruvate (i) $(\mu \mathrm{mol} / \mathrm{l})$ & $70 \pm 23$ & - & $60 \pm 13$ & $57 \pm 15$ & 0.33 \\
\hline Lactate (i) (mmol/l) & $0.62 \pm 0.25$ & - & $0.56 \pm 0.12$ & $0.60 \pm 0.16$ & 0.65 \\
\hline \multicolumn{6}{|l|}{ Glucose } \\
\hline Glucose (i) (mmol/l) & $4.4 \pm 0.4$ & $16.0 \pm 1.6^{\mathrm{a}}$ & $16.2 \pm 1.0^{\mathrm{a}}$ & $16.0 \pm 1.0^{\mathrm{a}}$ & 0.0001 \\
\hline Glucose $(\mathrm{cl})(\mathrm{mmol} / \mathrm{l})$ & $4.6 \pm 0.4$ & $5.2 \pm 0.6^{\mathrm{a}}$ & $4.8 \pm 0.5^{\mathrm{a}}$ & $4.9 \pm 0.5^{\mathrm{a}}$ & 0.0006 \\
\hline Insulin $(\mathrm{cl})(\mathrm{pmol} / \mathrm{l})$ & $26 \pm 7$ & $46 \pm 16^{\mathrm{a}}$ & $32 \pm 7^{a}$ & $37 \pm 12^{\mathrm{a}}$ & 0.23 \\
\hline C-peptide (cl) (nmol/l) & $0.44 \pm 0.14$ & $0.80 \pm 0.16^{\mathrm{a}}$ & $0.56 \pm 0.12^{\mathrm{a}}$ & $0.65 \pm 0.12^{\mathrm{a}}$ & 0.003 \\
\hline Pyruvate $(\mathrm{i})(\mu \mathrm{mol} / 1)$ & $74 \pm 23$ & - & $71 \pm 12^{\mathrm{a}}$ & $67 \pm 14$ & 0.15 \\
\hline
\end{tabular}

The presented blood glucose levels represent the mean value of all samples during the interval between the four time points. $\mathrm{i}=$ infused arm; $\mathrm{cl}=$ contralateral arm. $p$-level from Friedman test comparing the repeated measurements during the day. ${ }^{a}$ In- dicates significant difference compared with placebo values (Wilcoxon; $p<0.05$ with Bonferroni). Data represented as mean $\pm \mathrm{SD}$

Table 2. Ratios (infused: contralateral arm) of laser-Doppler fluxmetry (LDF) and forearm blood flow (FBF), and absolute values of capillary blood cell velocity (CBV), mean arterial pressure (MAP), and heart rate at baseline ( 0 hours), after $4 \mathrm{~h}$, and after $7 \mathrm{~h}$ of the glucose or placebo infusion

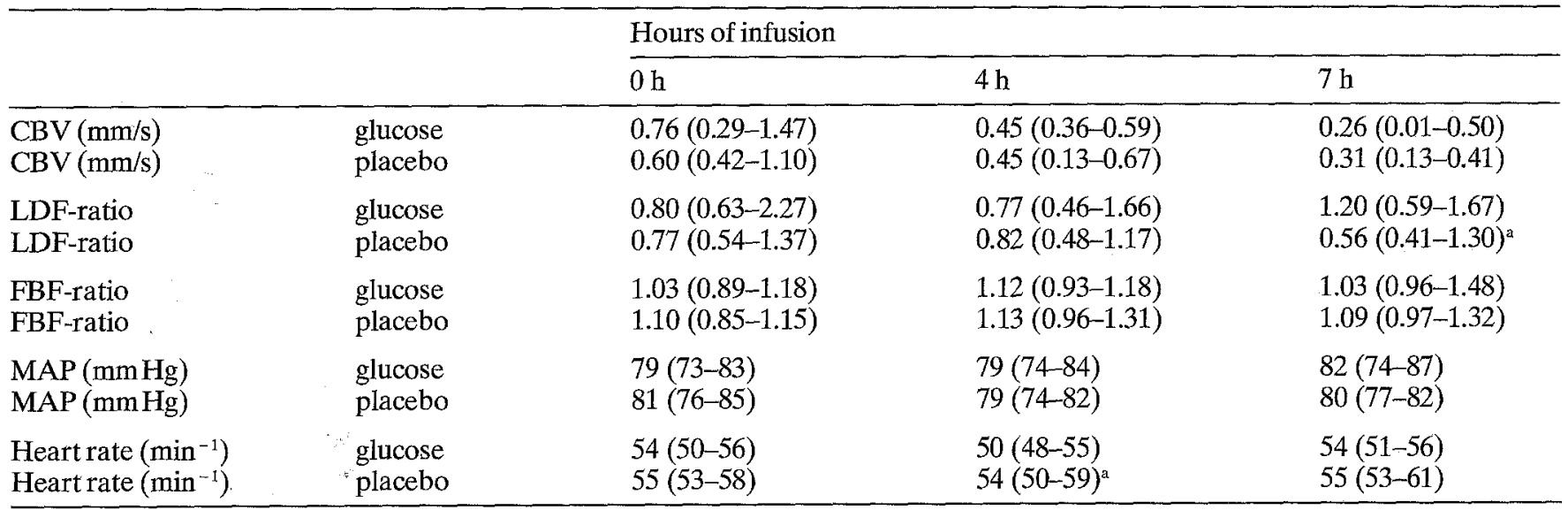

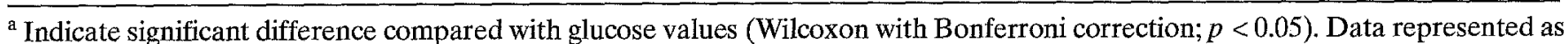
medians and interquártile ranges

Blood pressure was measured intraarterially using a Hewlett Packard $78205 \mathrm{C}$ monitor. Heart rate was recorded from the ECG.

Blood glucose was determined by the glucoseoxidase method on the ESAT 6660 analyzer (Eppendorf, Hamburg, Germany). Total insulin and C-peptide were determined by a commercial radioimmunoassay (Pharmacia, Uppsala, Sweden, and Byk-Sangtec, Dietzenbach, Germany, respectively). Lactate was determined by the lactateoxidase method, and pyruvate by the lactic dehydrogenase method. Both plasma adrenaline and noradrenaline were determined by HPLC according to the method of Van der Hoorn et al. [17].

Statistics and calculations. All data are presented as median values with interquartile ranges unless otherwise indicated. For each measurement period the ratio for LDF and FBF was calculated (infused arm divided by the contralateral arm). This calculated ratio corrects for all systemic factors that affect the regulation of blood flow in both arms (e.g. changes in blood pressure, level of arousal, hormonal changes etc.), and ensures that only the direct effects of locally infused substances on forearm blood flow are taken into account [18]. In an earlier study on diurnal variations of forearm macro and microcirculation, the FBF ratio was demonstrated to be stable during the day [19]. The present experiments were placebo controlled to correct for possible glucose-induced systemic effects, which would affect blood flow in both arms. The effects of local glucose infusion in CBV, LDF ratio, and FBF ratio were compared with the effects of local saline infusion after 4 and $7 \mathrm{~h}$. For each dose of noradrenaline the percentage change in $\mathrm{FBF}$ ratio (relative to pre-infusion 
values) was calculated at baseline ( 10.15 hours), after 4(14.30 hours), and after 7 -h glucose/saline infusion (17.30 hours) using the formula:

$\left.\frac{\left(F B F_{(i)(n a)} \times F B F_{(c)(s a h)}\right)}{\left(F B F_{(c)(n a)} \times F B F_{(i)(s a l)}\right)}-1\right) \times 100$

(i) = infused arm; (c) = contralateral arm; (na) = during noradrenaline infusion and $(\mathrm{sal})=$ during $0.9 \% \mathrm{NaCl}$ infusion into the infused arm.

The percentage change in FBF ratios for each dose of noradrenaline were compared during glucose/placebo infusions (within group), and between the glucose and placebo experiments (between group).

As the distribution of the CBV, LDF, and FBF data was not normal, the Friedman test (non-parametric two-way ANOVA) was used for analysis for multiple related samples and Wilcoxon paired sign test for paired analysis. When appropriate, the Bonferroni correction was used for multiple comparisons. $P$ values below 0.05 were considered statistically significant.

\section{Results}

Metabolic and hormonal effects. At baseline (10.15 hours) no differences were found in "systemic" glucose, insulin, and C-peptide levels between the glucose and placebo experiments (Table 1). During the intraarterial infusion of glucose, forearm venous blood glucose levels increased to a level of approximately $16 \mathrm{mmol} / \mathrm{l}$ (Table 1). Venous blood glucose levels in the contralateral arm ("systemic" glucose levels) showed a small increase during the local glucose infusions $(p<0.01)$, but did not reach a hyperglycaemic level (Table 1). As shown in Table 1, C-peptide levels also showed a small but statistically significant increase during the local glucose infusion. Probably, as a result of insulin extraction by the liver we did not measure a significant increase in insulin levels during local glucose infusions. In contrast, during the placebo infusions, insulin and C-peptide levels showed a small decrease during the day, whereas blood glucose did not change (Table 1). In both glucose and placebo experiments no major differences or changes were observed in lactate, pyruvate, and (nor)adrenaline levels (Table 1).

Baseline haemodynamics. No differences were observed in baseline haemodynamic values before the start of glucose or placebo infusions (Table 2 and Figures 1,2, and 3). Also, no differences could be observed in skin temperature or the baseline width of the erythrocyte columns (representing the capillary diameter) between the glucose or placebo experiments (data not shown). The percentage change in FBF ratio during the three cumulative doses of noradrenaline were similar before the start of glucose or placebo infusion (Fig. 4), also when they were expressed as percentage change in FVR ratio (data not shown; forearm vascular resistance $(\mathrm{FVR})=\mathrm{MAP} / \mathrm{FBF})$.

Haemodynamic effects of local hyperglycaemia. Blood pressure (MAP) increased slightly during the glucose
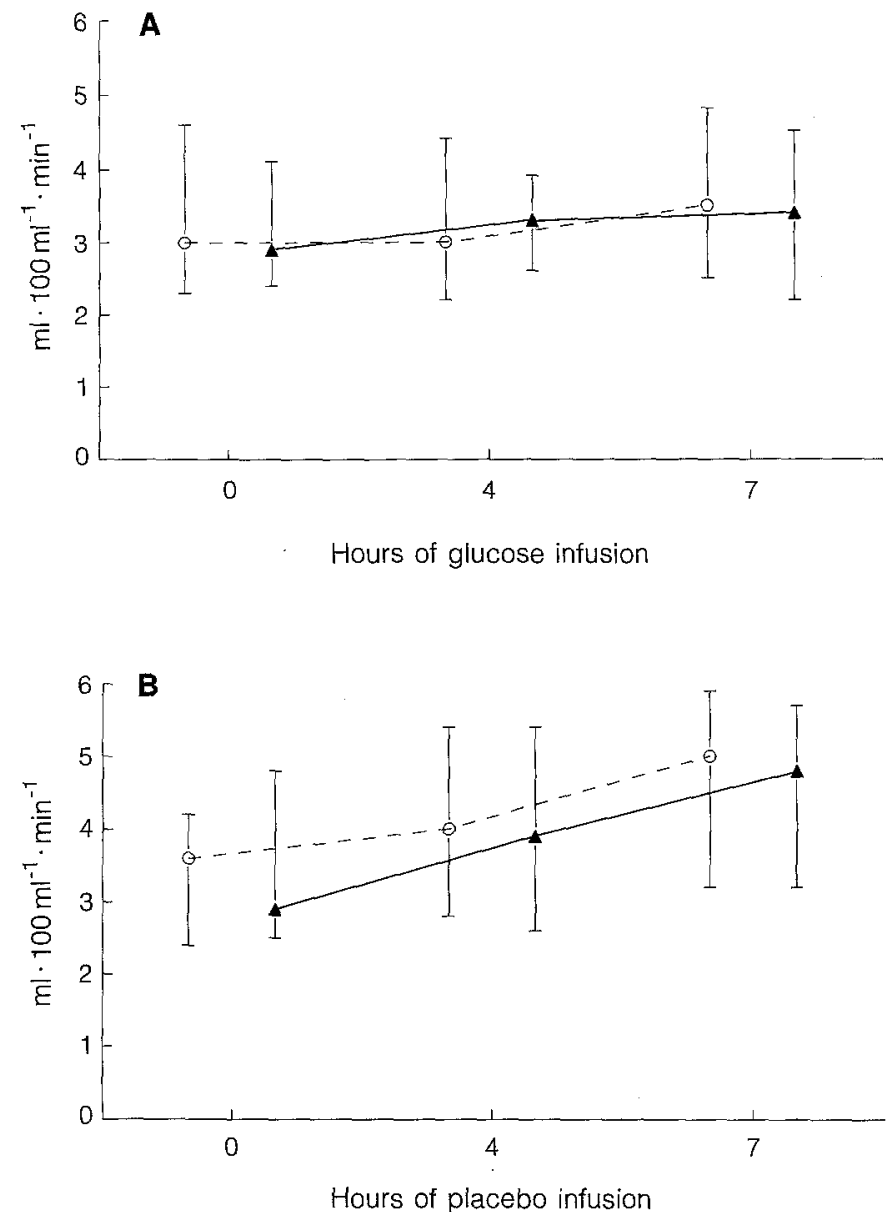

Fig. 1. (A,B) Median (and interquartile range) forearm blood flow (FBF) values $(n=12)$ of the infused $\operatorname{arm}(0)$ and the contralateral arm ( $\Delta$ ) before and after 4 and 7 h of intraarterialinfusion of $5 \%$ glucose (panel A) and placebo ( $0.9 \% \mathrm{NaCl}$; panel B9)

experiments (median change: 3 (1-6) $\mathrm{mm} \mathrm{Hg}$ after $7 \mathrm{~h}$, (Friedman; $p<0.05)$ ), and did not change during placebo experiments (median change: $-1(-2-+1) \mathrm{mm} \mathrm{Hg}$ (Friedman; NS)). However, no differences in MAP were observed between the glucose and placebo experiments (Table 2). Plasma adrenaline and noradrenaline levels did not change after $7 \mathrm{~h}$ glucose or placebo infusions (Table 1). Also heart rate did not change during glucose or placebo experiments, except after $4 \mathrm{~h}$ of infusion there was a difference in heart rate between glucose and placebo (Table 2). The effects of the 7-h local hyperglycaemia on forearm macro and microcirculation are depicted in Figures 1,2 and 3, and Table 2. The FBF ratios (infused: contralateral arm), FVR ratio (data not shown), and LDF ratio did not change during $7 \mathrm{~h}$ of glucose or placebo infusion (within group comparison; Table 2). Comparison of FBF ratios, LDF ratios, and CBV between the glucose and placebo experiments (between group comparison) at baseline $(0 \mathrm{~h})$ and after 4 and $7 \mathrm{~h}$ of infusion revealed no differences (except for LDF ratio after $7 \mathrm{~h}$, see further) These data suggest no local effect of hyperglycaemia on forearm macro and microcirculation (Table 2). As can been 

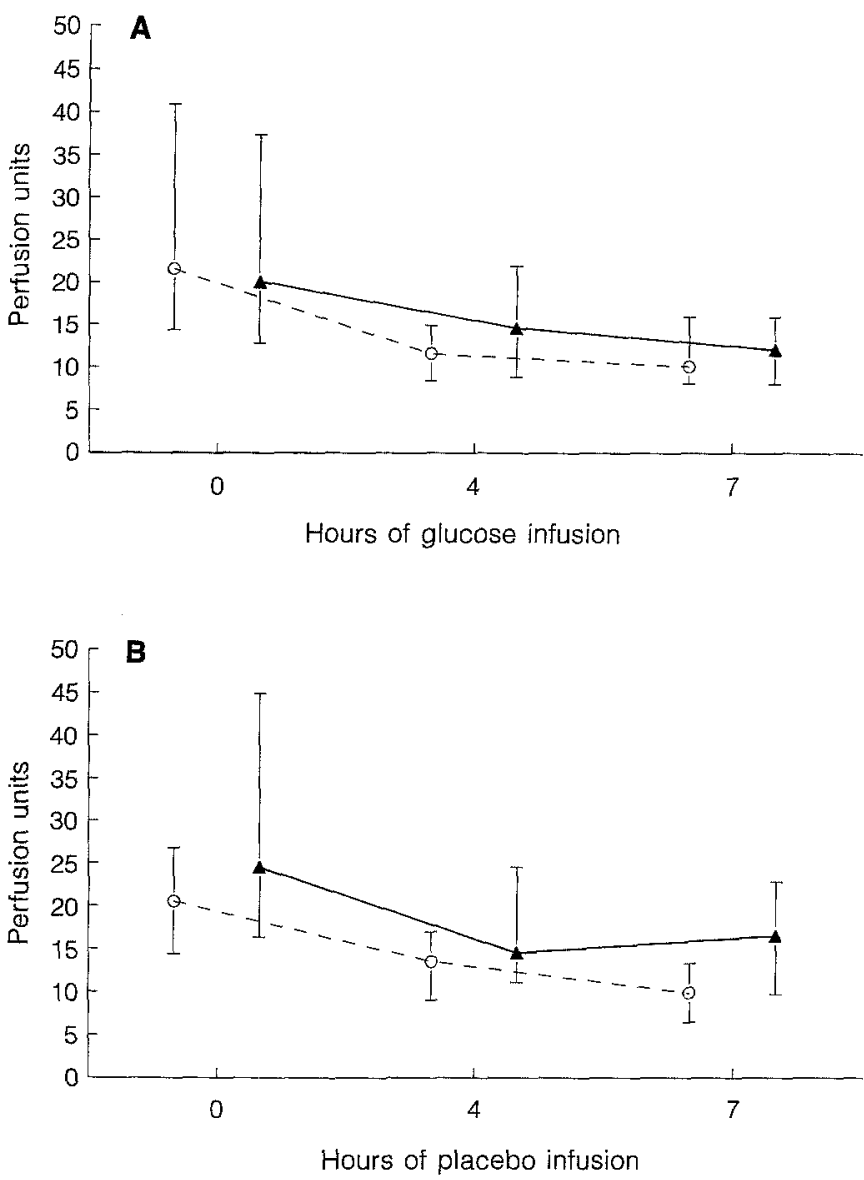

Fig.2. (A, B) Median (and interquartile range) laser-Doppler fluxmetry (LDF) values $(n=12)$ of the infused arm $(O)$ and the contralateral arm $(\Lambda)$ before and after 4 and $7 \mathrm{~h}$ of intraarterial infusion of $5 \%$ glucose (panel A) and placebo $(0.9 \% \mathrm{NaCl}$; panel B)

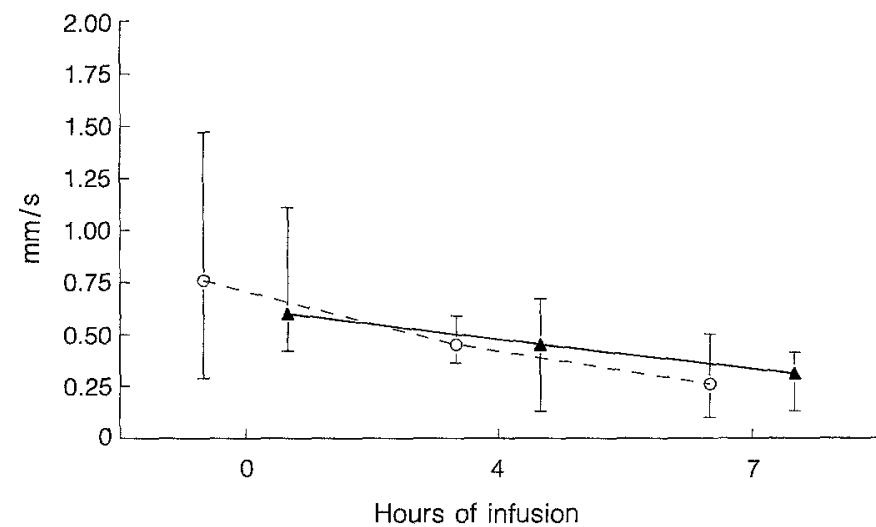

Fig. 3. Median (and interquartile range) capillary blood cell velocity (CBV) values $(n=7)$ of the infused arm before and after 4 and $7 \mathrm{~h}$ of intraarterial infusion of $5 \%$ glucose $(O)$ and placebo $(0.9 \% \mathrm{NaCl})(\Delta)$

seen in Figure 2 and Table 2, the difference in LDF ratio after $7 \mathrm{~h}$ glucose or placebo infusion is probably a result of a relative increase in LDF of the contralateral arm in the placebo group, instead of a local effect of glucose on the infused arm.
A.J.H.M.Houben et al.: Hyperglycaemia and forearm blood flow

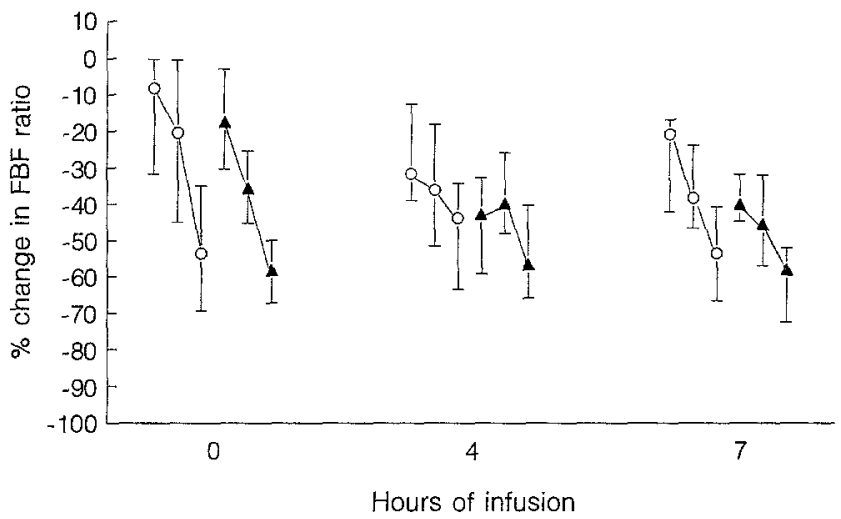

Fig.4. Percentage change in forearm blood flow ratio (infused: contralateral arm) $(n=12)$ during three cumulative doses of noradrenaline: $0.025,0.1$, and $0.4 \mu \mathrm{g} / \mathrm{min}$, before and after 4 and $7 \mathrm{~h}$ of intraarterial glucose $(O)$ or placebo $(A)$ infusion. Data are expressed as median and interquartile ranges. No differences were observed

Although the FBF ratios were not different between glucose and placebo (Table 2), the increase in absolute FBF values of both separate arms after $7 \mathrm{~h}$ was less during the glucose experiments than during the placebo experiments (Fig.1): in the infused arm $58 \%(23-101)$ vs $2 \%(-25-+56)$, and in the the contralateral arm $23 \%(10-90)$ vs $5 \%(-11-+24)$ (glucose vs placebo, $p=0.03$ and $p=0.02$, respectively). FVR showed similar changes in both arms (data not shown). No differences were observed in the changes in skin temperature between glucose and placebo (data not shown). The width of the erythrocyte columns was not changed after $7 \mathrm{~h}$ glucose or placebo infusion (data not shown).

Figure 4 depicts the percentages change in FBF ratio to $0.025,0.1$, and $0.4 \mu \mathrm{g} / \mathrm{min}$ noradrenaline before and during glucose and placebo experiments. The reactivity to noradrenaline did not change during the glucose or placebo experiments (within group comparison), nor were any differences in reactivity observed between glucose and placebo infusions at each moment (between group comparison).

\section{Discussion}

The results of the present study indicate that total forearm and skin microcirculatory blood flow (nutritive as well as thermoregulatory) are not affected by local hyperglycaemia $(\approx 16 \mathrm{mmol} / \mathrm{l}$ ) for $7 \mathrm{~h}$. In addition, forearm vasoreactivity to noradrenaline was not affected by the intraarterial glucose infusion.

Animal studies suggest that hyperglycaemia directly affects the ability of blood vessels to autoregulate blood flow $[8,9]$. Such haemodynamic changes might be one of the priming mechanisms in the development of diabetic microangiopathy [1]. Indeed, in healthy 
man induction of systemic hyperglycaemia results in an increase in forearm/leg blood flow in some studies, and in renal hyperfiltration [20-22]. However, as substantial secondary hormonal changes occur during systemic hyperglycaemia, these results are difficult to interpret. In the present study, glucose was infused intraarterially in the forearm to determine the effects of local forearm hyperglycaemia (approximately $16 \mathrm{mmol} / \mathrm{l}$ ) for several hours, on peripheral macro and microcirculation. This 7-h local hyperglycaemia did not induce changes in forearm macro and microcirculatory blood flow of the infused arm.

It may be that the following confounding factors have influenced the present results. As demonstrated here and in an earlier study [19], FBF increases during the day, which is probably based on a circadian rhythm in sympathetic vasoconstrictor activity [23]. In contrast, skin microcirculatory blood flow (LDF) decreases particularly in the morning, probably due to an acclimatization phenomenon [19]. As in the present study FBF and LDF were measured on both the infused and the contralateral arm, it seems unlikely that these diurnal variations in blood flow might mask any local effect of glucose on peripheral blood flow. In the present model, possible local vasoactive properties of glucose would lead to haemodynamic changes in the infused arm only and not in the contralateral arm, resulting in a change of the FBF or LDF ratio. Possible systemic changes would lead to haemodynamic changes in both arms, thereby not influencing the ratio.

In comparison to the placebo experiments, the local glucose infusion resulted in a small increase in systemic glucose levels, and stimulated insulin secretion. Both insulin and C-peptide have been suggested to exert vasodilator effects [24,25], which could mask a haemodynamic effect of local hyperglycaemia. However, in comparison to placebo infusion peripheral blood flow was not increased during the local glucose infusions, which implies that the changes in systemic glucose levels and insulin secretion were too small to have vasodilator effects.

During the local hyperglycaemia minute systemic haemodynamic changes were observed: a small increase in MAP and a diminished increase in absolute FBF, while plasma catecholamines did not change. These systemic haemodynamic changes suggest relative vasoconstriction. However, in our opinion the magnitude of the changes in MAP and FBF, which remain unexplained, was too small to mask a possible haemodynamic effect of the local glucose infusion. As mentioned before, changes in MAP should effect haemodynamics in both arms, thereby not influencing the FBF ratio.

In the present study only male volunteers were included to avoid possible influences of the female menstrual cycle on peripheral haemodynamics. It could be speculated that glucose-induced vascular changes can only be observed in women, however, other studies contradict this speculation [26].

The observed difference in LDF ratio after $7 \mathrm{~h}$ of glucose or placebo infusion is probably an artefact. In contrast to the decline of the LDF signal of both arms during glucose, and of the infused arm during placebo, the LDF signal of the contralateral arm during placebo shows a different pattern, resulting in a higher median signal at 17.30 hours. This probably causes the erroneous low LDF ratio after 7 -h placebo. infusion.

Although animal studies suggest that $2-5 \mathrm{~h}$ of local hyperglycaemia in the $16 \mathrm{mmol} / 1$ range can induce vascular haemodynamic changes [9], it is possible that the level and/or duration of local hyperglycaemia was insufficient to affect the forearm vasculature. Due to possible heterogeneity in sensitivity to hyperglycaemia for different tissues, the forearm muscle and skin vasculature may require a more severe or longer period of local hyperglycaemia to induce haemodynamic change. The reported hyperperfusion observed in these tissues of patients with short-term IDDM $[2,3]$ might, therefore, be the result of relatively high peripheral insulin levels or systemic effects of hyperglycaemia instead of local hyperglycaemia. Finally, it seems unlikely that the glucose did not reach the vascular endothelial and/or smooth muscle cells, as the glucose uptake in these cells is predominantly insulin independent and occurs by facilitated diffusion [27]. The fact that the venous pyruvate and lactate levels of the infused arm were unaltered after $7 \mathrm{~h}$ of local hyperglycaemia suggests that no major changes in glucose metabolism of the forearm muscle tissue occurred. However, a possible increase in forearm lactate and pyruvate production might be masked by a decreased production at other sites (e.g. splanchnic area) [28].

The present data demonstrate that a 7-h local hyperglycaemia does not change forearm vasoreactivity to noradrenaline in man. Animal (in vitro) studies suggest that diabetes induces enhanced vasoreactivity to noradrenaline [10], although some could not demonstrate such an effect [29]. Morff [11] demonstrated that in animals the enhanced vasoreactivity to noradrenaline in diabetes is probably a short-term effect, which normalizes after 16 to 32 weeks after induction of diabetes. Indeed, vasoreactivity to noradrenaline has been reported to be unchanged in patients who have had uncomplicated diabetes for several years $[2,30]$. However, in long-term diabetic patients with retinopathy [31] the pressor response to noradrenaline was increased, and in patients with microalbuminuria [12] or autonomic neuropathy [13] vasoreactivity to noradrenaline was found to be increased.

In conclusion, in contrast to several animal studies, local hyperglycaemia (approximately $16 \mathrm{mmol} / \mathrm{l}$ ) for $7 \mathrm{~h}$ does not affect forearm macro and microcirculatory blood flow or vascular reactivity to noradrenaline in man. 
Acknowledgements. This study was supported by grant 91.103 from the Diabetes Fonds Nederland. The authors thank Mr. P.Claessens for excellent technical support.

\section{References}

1. Parving $\mathrm{H}-\mathrm{H}$, Viberti GC, Keen $\mathrm{H}$, Christiansen JS, Lassen NA (1983) Hemodynamic factors in the genesis of diabetic microangiopathy. Metabolism 32: 943-949

2. Calver A, Collier J, Vallance P (1992) Inhibition and stimulation of nitric oxide synthesis in the human forearm arterial bed of patients with insulin-dependent diabetes. J Clin Invest 90: $2548-2554$

3. Houben AJHM, Schaper NC, Slaaf DW, Tangelder GJ, Nieuwenhuijzen Kruseman AC (1992) Skin blood cell flux in insulin-dependent diabetic subjects in relation to retinopathy or incipient nephropathy. Eur J Clin Invest 22: 67-72

4. Mathiesen ER, Hilsted J, Feldt-Rasmussen B, Bonde-Petersen F, Christensen NJ, Parving HH (1985) The effect of metabolic control on hemodynamics in short-term insulin-dependent diabetic patients. Diabetes 34: 1301-1305

5. Christiansen JS, Gammelgaard J, Tronier B, Svendsen PA, Parving HH (1982) Kidney function and size in diabetics before and during initial insulin treatment. Kidney Int 21: $683-$ 688

6. Grunwald JE, Brucker AJ, Schwartz SS et al. (1990) Diabetic glycemic control and retinal blood flow. Diabetes 39: 602-607

7. Sandeman DD, Shore AC, Tooke JE (1992) Relation of skin capillary pressure in patients with insulin-dependent diabetes mellitus to complications and metabolic control. New Eng J Med 327: 760-764

8. Bohlen HG, Hankins KD (1982) Early arteriolar and capillary changes in streptozotocin-induced diabetic rats and intraperitoneal hyperglycaemic rats. Diabetologia $22: 344-348$

9. Williamson JR, Ostrow E, Eades D et al. (1990) Glucose-induced microvascular functional changes in nondiabetic rats are stereospecific and are prevented by an aldose reductase inhibitor. J Clin Invest 85: 1167-1172

10. Friedman JJ (1989) Vascular sensitivity and reactivity to norepinephrine in diabetes mellitus. Am J Physiol 256: H1134-H1138

11. Morff RJ (1990) Microvascular reactivity to norepinephrine at different arteriolar levels and durations of streptozocin-induced diabetes. Diabetes 39: 354-360

12. Bodmer CW, Patrick AW, Williams G (1992) Exaggerated sensitivity to NE-induced vasoconstriction in IDDM patients with microalbuminuria. Possible etiology and diagnostic implications. Diabetes 41:209-214

13. Eichler HG, Blaschke TF, Kraemer FB, Ford GA, BlochlDaum B, Hoffman BB (1992) Responsiveness of superficial hand veins to $\alpha$-adrenoceptor agonists in insulin-dependent diabetic patients. Clin Sci 82: 163-168

14. Houben AJHM, Schaper NC, Nieuwenhuijzen Kruseman AC (1993) Acute effects of local hyperglycaemia on peripheral blood flow in man. Diab Med 10: 39-43

15. Slaaf DW, Arts T, Jeurens TJM, Tangelder GJ, Reneman RS (1984) Electronic measurement of red blood cell velocity and volume flow in microvessels. In: Chayen J, Bitensky L (eds) Investigative microtechniques in medicine and biology. Vol 1, Marcel Dekker, Inc. New York
16. Cooper KE, Edholm OG, Mottram RF (1955) The blood flow in skin and muscle of the human forearm. J Physiol 128: 258-267

17. Van der Hoorn FAJ, Boomsma F, Man in 't Veld AJ, Schalekamp MADH (1989) Determination of catecholamines in human plasma by high-performance liquid chromatography: comparison between a new method with fluorescence detection and an established method with electrochemical detection. J Chromatogr 487: 17-28

18. Greenfield ADM, Patterson GC (1954) Reactions of the blood vessels of the human forearm to increase in transmural pressure. J Physiol 125: 508-524

19. Houben AJHM, Slaaf DW, Huvers FC, de Leeuw PW, Nieuwenhuijzen Kruseman AC, Schaper NC (1994) Diurnal variations in total forearm and skin microcirculatory blood flow in man. Scand J Clin Lab Invest 54: 161-169

20. Bülow J, Astrup A, Christensen NJ, Kastrup J (1987) Blood flow in skin, subcutaneous adipose tissue and skeletal muscle in the forearm of normal man during an oral glucose load. Acta Physiol Scand 130: 657-661

21. Laakso M, Edelman SV, Olefsky JM, Brechtel G, Wallace P, Baron AD (1990) Kinetics of in vivo muscle insulin-mediated glucose uptake in human obesity. Diabetes 39: 965-974

22. Christiansen JS, Frandsen M, Parving HH (1981) Effect of intravenous glucose infusion on renal function in normal man and in insulin dependent diabetics. Diabetologia 21 : 368-372

23. Panza JA, Epstein SE, Quyyumi AA (1991) Circadian variation in vascular tone and its relation to $\alpha$-sympathetic vasoconstrictor activity. $N$ Eng J Med 325: 986-990

24. Anderson EA, Hoffman RP, Balon TW, Sinkley CA, Mark AL (1991) Hyperinsulinemia produces both sympathetic neural activation and vasodilation in normal humans. J Clin Invest $87: 2246-2252$

25. Johansson BL, Linde B, Wahren J (1992) Effects of C-peptide on blood flow, capillary diffusion capacity and glucose utilization in the exercising forearm of type 1 (insulin-dependent) diabetic patients. Diabetologia 35: 1151-1158

26. Williamson JR, Rowold E, Chang K et al. (1986) Sex steroid dependency of diabetes-induced changes in polyol metabolism, vascular permeability, and collagen cross-linking. Diabetes 35: 20-27

27. Corkey RF, Corkey BE, Gimbrone MA (1981) Hexose transport in normal and SV40-transformed human endothelial cells in culture. J Cell Physiol 106: 425-434

28. Radziuk J, Inculet R (1983) The effects of ingested and intravenous glucose on forearm uptake of glucose and glucogenic substrate in normal man. Diabetes 22: 977-981

29. Fulton DJR, Hodgson WC, Sikorski BW, King RG (1991) Attenuated responses to endothelin-1, $\mathrm{KCl}$ and $\mathrm{CaCl}_{2}$, but not noradrenaline, of aortae from rats with streptozotocininduced diabetes mellitus. Br J Pharmacol 104: 928-932

30. Halkin A, Benjamin N, Doktor HS, Todd SD, Viberti G, Ritter JM (1991) Vascular responsiveness and cation exchange in insulin-dependent diabetes. Clin Sci 81: 223-232

31. Christlieb AR, Janka HU, Kraus B et al. (1976) Vascular reactivity to angiotensin II and to norepinephrine in diabetic subjects. Diabetes 25: 268-274 